\title{
Pelatihan Berpikir Praktis Melalui Permainan Komputer untuk Siswa SD ISBA 2 Semarang
}

\author{
Practical Thinking Training using Computer Games for Students at SD ISBA 2 \\ Semarang \\ Sendi Novianto ${ }^{1}$, Acun Kardianawati ${ }^{2}$, Umi Rosyidah ${ }^{3}$, Hanny Haryanto ${ }^{4}$ \\ ${ }^{1,2,3}$ Universitas Dian Nuswantoro; J1. Imam Bonjol 207 Semarang, (+6224) 3517261 \\ E-mail: ${ }^{1}$ sendi.novianto@dsn.dinus.ac.id, ${ }^{2}$ acunkardianawati@yahoo.co.id, \\ ${ }^{3}$ umi.rosyidah@dsn.dinus.ac.id, ${ }^{4}$ hanny.haryanto@dsn.dinus.ac.id
}

\begin{abstract}
Abstrak
Bermain adalah salah satu kegiatan anak yang tidak dapat dihindari. Kegiatan tersebut adalah kebutuhan utama yang wajib dipenuhi untuk menunjang masa depan mereka. Dari permainan yang dimainkan oleh anak-anak, biasanya merupakan cerminan dari sikap mereka dimasa depan. Dengan adanya perkembangan didunia komputer, permainan menjadi salah satu favorit anak-anak. Untuk dapat memberikan masukan yang positif guna membangun pikiran kritis dalam memecahkan permasalahan, kita dapat memberikan dan mengarahkan anak-anak untuk memainkan game yang bisa membentuk pola tersebut. Code.org adalah salah satu lembaga non profit yang membuat game untuk melatih anak-anak belajar coding pemrograman melalui permainan komputer. Terbukti anak-anak yang memainkan game ini, menjadikan mereka lebih semangat dalam memecahkan permasalahan yang ada.
\end{abstract}

Kata kunci: Berpikir praktis, Permainan Komputer, Siswa SD

\begin{abstract}
Play is one of the activities of children that can not be avoided. These activities are the main needs that must be met to support their future. From the games played by children, it is usually a reflection of their attitude in the future. With the development in the world of computers, games have become one of the children's favorites. To be able to provide positive input to build critical thinking in solving problems, we can provide and direct children to play games that can form these patterns. Code.org is one of the non-profit institutions that makes games to train children to learn coding programming through computer games. Proven children who play this game, making them more enthusiastic in solving existing problems.
\end{abstract}

Keywords: Practical Thinking, Computer Games, Elementary Students

\section{PENDAHULUAN}

Sekolah dasar merupakan pondasi awal dimana anak-anak kita nantinya akan diberikan ilmu pengetahuan dasar untuk guna mempersiapkan diri untuk melangkah ke jenjang yang lebih tinggi. Dengan adanya kemajuan teknologi, dunia pendidikan yang ada saat ini pun ikut berkembang untuk dapat mengimbangi perkembangan teknologi yang ada. Untuk dapat mengimbangi perkembangan jaman yang ada dengan dunia pendidikan, diperlukan adanya perubahan dari cara mengajar dan juga perlu adanya pemampatan materi yang disampaikan agar siswa tidak tertinggal terlalu jauh nantinya[1].

Teknologi multimedia sudah berkembang sangat pesat sekali, bahkan sampai saat ini sudah mengarah ke arah virtual reality, dimana pemakai teknologi ini bisa langsung berinteraksi dengan objek yang ada didalamnya serta dapat memanipulasinya sesuai dengan keingingan dari pemainnya. Permainan game sangat disukai oleh semua kalangan usia, baik mulai dari anakanak sampai dengan orang dewasa[2]. Tidak semua permainan dapat di mainkan oleh anak-anak usia dini, hal ini dikarenakan adanya adegan-adegan yang tidak patut dicontoh seperti halnya 
penembakan, atau pemukulan dan sebagainya. Orang tua dituntut juga harus menjadi selektif terhadap adanya permainan yang ada saat ini, sehingga anaknya tidak terpengaruh terhadap permainan yang dimainkannya[3]-[5].

Permainan yang sesuai untuk anak-anak usia dini adalah jenis permainan yang dapat mengasah kemampuan berpikir mereka, sehingga dapat segera tanggap dalam menghadapi berbagai masalah yang mereka temui[6]. Dengan cara ini, anak-anak dihadapkan dengan berbagai masalah yang di hadapinya, dan dituntut untuk menemukan solusi dari permasalahan yang ada tanpa merasa mereka sedang belajar[7]. Pembelajaran dengan cara ini dipandang mampu meningkatkan pemahaman mereka ke tingkat lebih lanjut[8]-[10].

Untuk dapat memberikan kebutuhan akan pembelajaran ke tingkat yang lebih tinggi lagi, diperlukan juga pengajar yang mampu melakukan hal tersebut. Kombinasi dari pengajar dan siswa yang saling terkait akan dapat menghasilkan output hasil pembelajaran yang lebih optimal. Saat ini pembelajaran dengan menggunakan media komputer yang diajarkan di SD $\mathrm{Hj}$ Isriati 2 Semarang hanya seputar dasar dari pemakaian komputer. Mulai dari operasional komputer dari menghidupkan dan mematikan komputer sampai dengan penggunaan aplikasi standart dari microsoft seperti halnya microsoft paint, microsoft word, microsoft excel, microsoft power point. Dari materi yang diberikan, dapat diketahui bahwa peranan komputer belum dipergunakan secara maksimal untuk membantu proses perkembangan murid-murid di sekolah tersebut.

Untuk dapat mengoptimalkan peranan komputer terhadap perkembangan cara berpikir siswa, diperlukannya stimulus untuk yang berkaitan dengan komputer itu sendiri agar siswa merasa tertarik dan nyaman dalam berinteraksi dengan komputer serta sekaligus dapat melatih daya pikir dan motorik anak. Dengan meningkatnya kemampuan daya pikir dan kreativitas siswa, tentunya akan mempermudah mereka dalam menyelesaikan persoalan yang akan dihadapinya ketika menghadapi pelajaran dalam kegiatan belajar mengajar baik di lingkungan sekolah maupun di rumah.

Mengingat perkembangan teknologi di dunia modern ini, maka pelaksanaan pengabdian ini sebagai mitra dalam hal ini adalah SD Hj. Isriati Baiturrahman 2 Semarang akan diberi pelatihan untuk siswa sebagai peserta dan guru sebagai pendamping dalam hal berpikir praktis melalui permainan komputer. Dengan pelatihan tersebut diharapkan siswa-siswa di SD $\mathrm{Hj}$. Isriati Baiturrahman 2 Semarang dapat lebih mengoptimalkan kemampuan berpikir praktis dalam menyelesaikan berbagai permasalahan dalam proses belajar di jenjangnya. Selain itu, para guru di lingkungan SD $\mathrm{Hj}$. Isriati Baiturrahman 2 Semarang yang ikut dalam pendampingan juga bisa mengaplikasikannya ke siswa di jenjang lainnya.

\section{METODE PELAKSANAAN}

Metode pelaksanaan dari kegiatan ini adalah dengan melakukan pelatihan berupa tutorial dan praktek dimana tutor akan memberikan langkah-langkah dasar kemudian akan langsung diikuti dan dipraktekkan oleh peserta. Secara detail, pelaksanaan kegiatan pengabdian ini terdiri dari beberapa tahap. Berikut merupakan tahapan-tahapan yang dilakukan:

1. Melakukan koordinasi dengan pihak pengurus $\mathrm{SD} \mathrm{Hj}$. Isriati Baiturrahman 2. Dilakukan untuk memastikan daftar peserta yang akan mengikuti program pelatihan.

2. Menentukan dan membuat detail materi yang akan diberikan.

3. Menentukan waktu dan tempat penyelenggaraan pelatihan. Waktu disesuaikan dengan waktu luang peserta dan pemateri.

4. Membuat undangan bagi mitra. Undangan diberikan pada peserta untuk informasi waktu, tempat dan agenda pelatihan.

5. Menyiapkan sarana dan prasarana kegiatan, lab komputer, laptop, desktop dan proyektor. Hal ini dilakukan agar pelaksaan kegiatan dapat berlangsung dengan baik dan lancar.

6. Pelaksanaan tutorial dan praktek yang dilakukan langsung di tempat. Tutorial yang 
diberikan akan langsung dipraktekkan oleh peserta.

7. Adanya bimbingan dan konsultasi yang dilakukan untuk membantu peserta yang mengalami kesulitan.

8. Melakukan pengarsipan dan dokumentasi. Administrasi yang meliputi undangan peserta, surat menyurat, dokumentasi foto, dan daftar hadir diarsipkan dan untuk pembuatan laporan.

9. Membuat laporan. Hal ini dilakukan guna memberikan laporan kepada instansi bahwa kegiatan yang dilakukan benar-benar dilakukan.

10. Menyiapkan tim pendamping untuk monitoring. Hal ini digunakan untuk memantau perkembangan dan ketrampilan hasil pelatihan.

\section{HASIL DAN PEMBAHASAN}

Kegiatan ini diawali dengan perkenalan cara manusia berpikir, yaitu dimulai dengan adanya permasalahan yang dihadapi saat itu, otak manusia akan secara otomatis aktif untuk menemukan solusi yang mungkin bisa dilakukan terhadap permasalahan yang ditemuinya. Sebagai contohnya, ketika manusia merasakan lapar, maka perut akan berbunyi, secara otomatis manusia akan mencari solusi untuk memenuhi kebutuhannya untuk makan, jika disekitarnya ada mie instant, maka manusia itu akan memasak mie instant itu untuk dijadikan sebagai solusi atas rasa lapar yang dirasakannya.

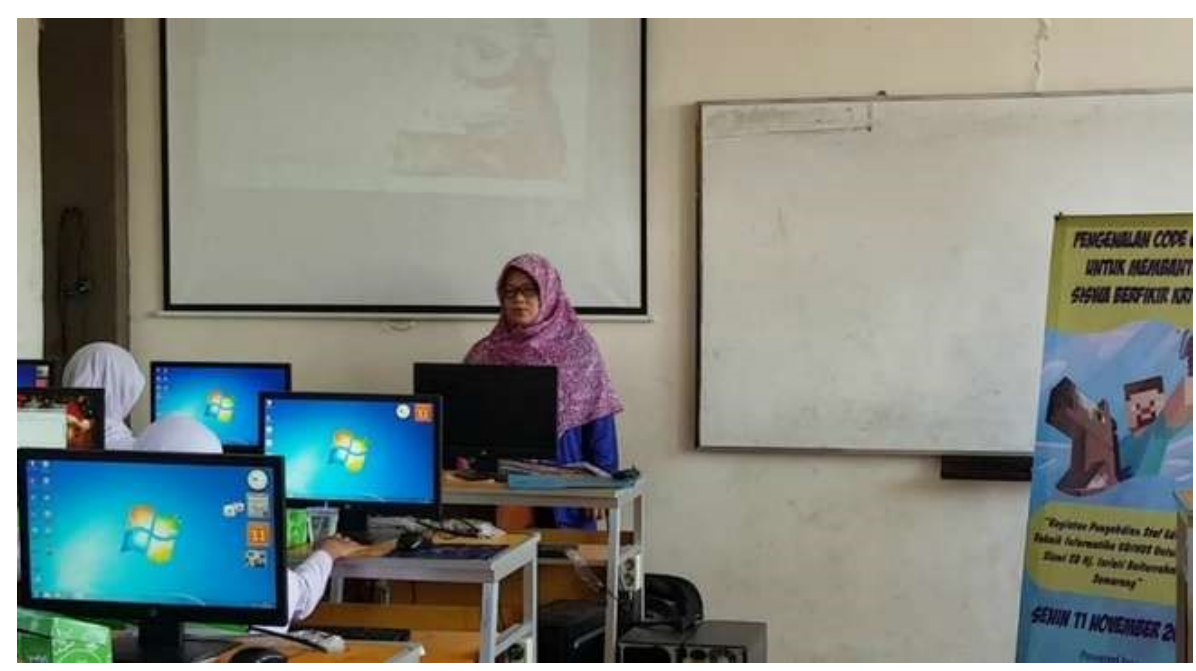

Gambar 1. Pembukaan acara pengabdian

Ketika para peserta sudah memulai memahami cara kerja dari pikiran manusia dalam mengatasi masalah yang ada dengan membangun solusi untuk mengatasi masalah tersebut. Kami melanjutkan dengan memberikan pengertian computer dengan menggunakannya sebagai analogi manusia, dimana otak manusia sebagai analogi prosesor dalam computer, mulut manusia sebagai speaker dalam computer, telinga manusia sebagai microphone dalam computer. Manusia bisa bekerja ketika ada tenaga atau ada perintah, sedangkan computer bisa bekerja ketika ada inputan perintah. Ketika tenaga ataupun perintah di terima oleh manusia, maka manusia akan bisa mulai bekerja dan berpikir terhadap perintah yang dia terima. Demikian juga dengan computer, ketika computer sudah menerima inputan berupa perintah, maka perintah 
tersebut akan diproses oleh prosesor. Dari hasil kegiatan bekerja dan memproses tersebut, maka baik manusia dan komputer maupun akan mendapatkan output berupa hasil dari proses yang sudah dikerjakan sebelumnya. Itulah analogi proses kerja atara computer dengan manusia yang kita perkenalkan. Dengan adanya analogi ini, diharapkan para siswa bisa lebih mengenal computer lebih baik, baik pengenalan alat-alat yang dijadikan sebagai input, proses serta alatalat yang dijadikan sebagai output dari hasil proses tersebut.
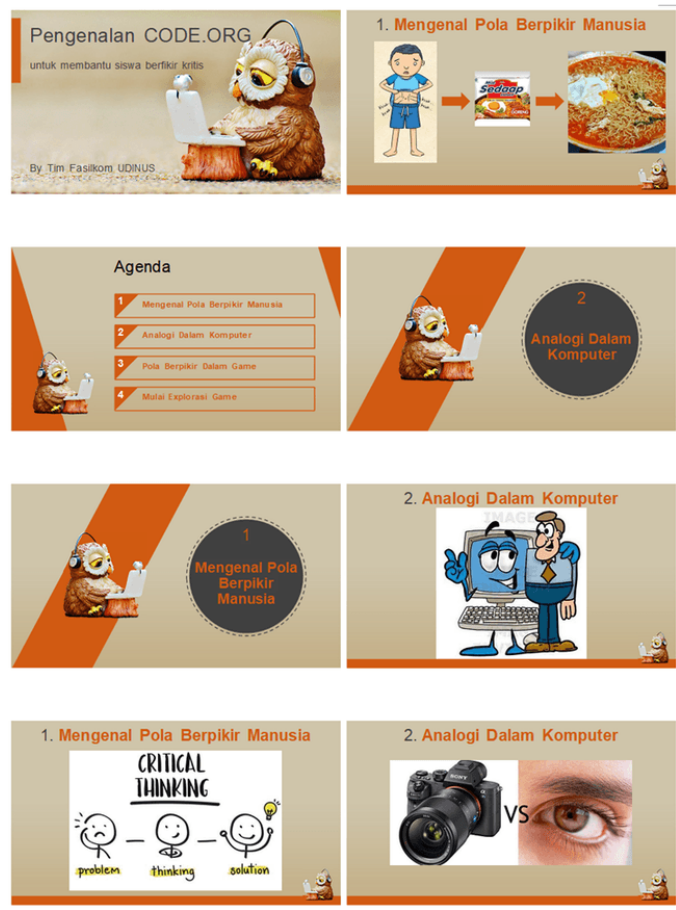
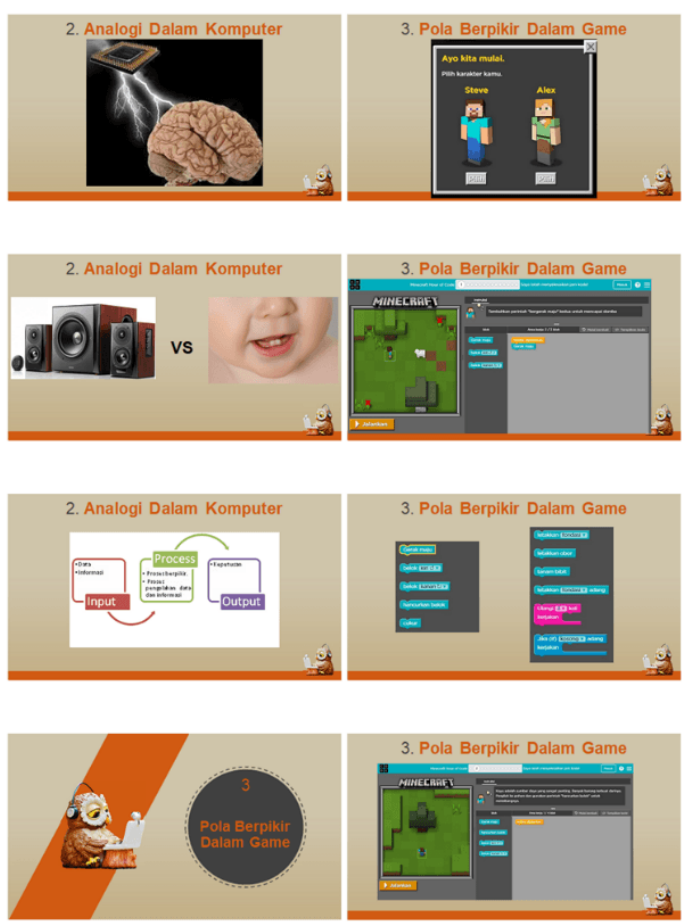

Gambar 2 Slide Presentasi

Presentasi berikutnya adalah pengenalan game yang akan dijadikan sebagai bahan pelatihan dalam kegiatan ini. Game yang akan dipilih diambil dari situs code.org, sedangkan tema game yang akan dipakai adalah Minecraft, dimana game Minecraft saat ini merupakan salah satu game yang sedang naik daun di kalangan anak-anak. Dalam presentasi ini, kita hanya mengenalkan bagian-bagian dalam game, baik berupa kontrolnya, serta pemahaman perintahperintah untuk dapat mengontrol game tersebut untuk mencapai tujuan dari tiap levelnya. Analisa dan logika dalam penanganan permasalah yang ada ditiap levelnya sangat dibutuhkan agar level tiap game dapat terpenuhi dan dilewati guna mendapatkan tujuan akhir, yaitu pemahaman masalah dan solusi disertai dengan reward yang berupa sertifikat yang nantinya akan diberikan kepada siswa-siswa yang berhasil menyelesaikan semua level yang tersedia dalam permainan tersebut.

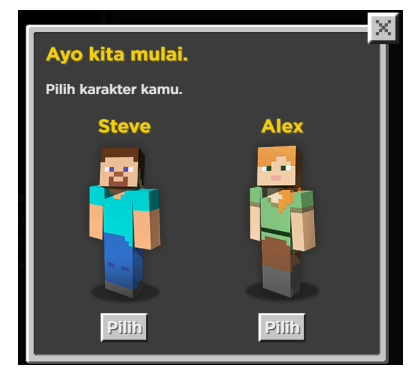

Gambar 3 Tokoh Utama Dalam Game 


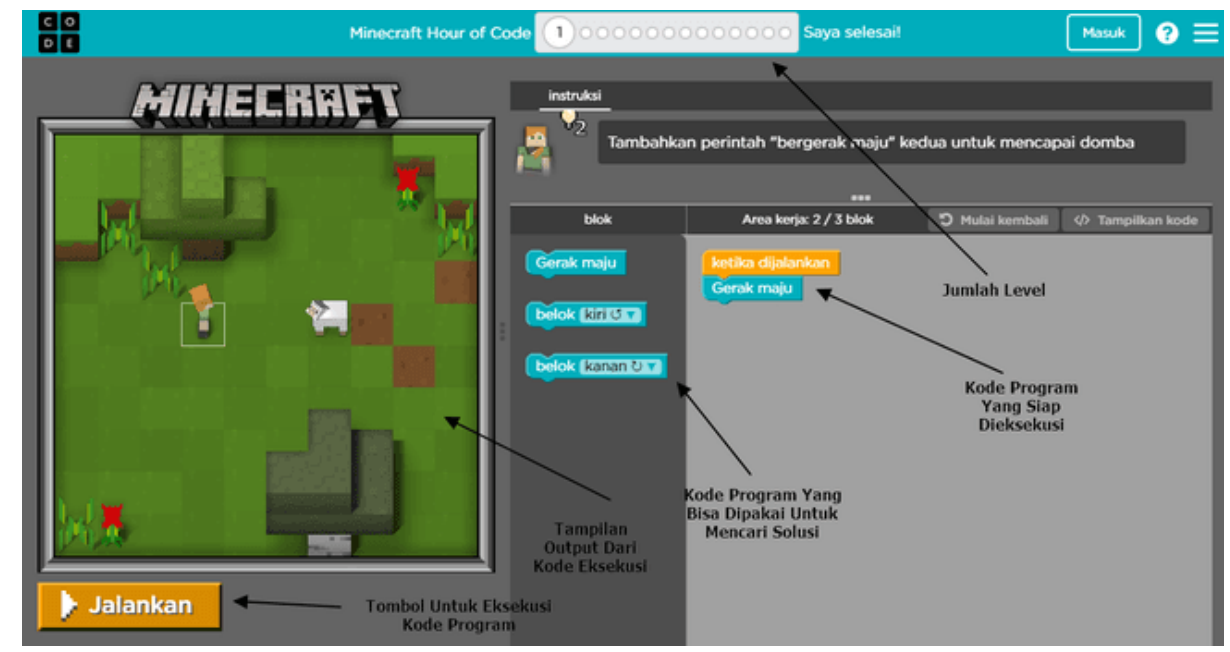

Gambar 4 Interface Game yang dipakai

Pada tahap praktek permainan game untuk memecahkan masalah yang ada pada tiap levelnya, terlihat bahwa para siswa sangat antusias dalam mencari solusi secara mandiri, selain itu juga pada siswa juga aktif dalam melakukan explore terhadap game tersebut. Aksi diskusi juga tidak bisa lepas dalam kegiatan ini, dimana dengan tujuan yang sama, yaitu memenangkan tiap levelnya, sharing informasi dan pengalaman juga terjadi dibagian praktek ini. Dalam hal ini dapat kita lihat bahwa peranan game sangat terlihat sekali dapat menjadikan para siswa menjadi aktif dalam menemukan solusi dari permasalahan yang ada pada tiap level permainan yang kita suguhkan. Dari proses tersebut, kami mencoba memberikan stimulus berupa lomba siapa yang tercepat menyelesaikan semua level yang ada, maka mereka akan mendapatkan sertifikat. Dengan adanya stimulus yang kita berikan kepada para siswa, mereka menjadi lebih bersemangat untuk dapat menyelesaikan semua levelnya. Banyak dari para siswa yang termotivasi untuk berlomba siapa yang paling cepat mencapai level terakhir.
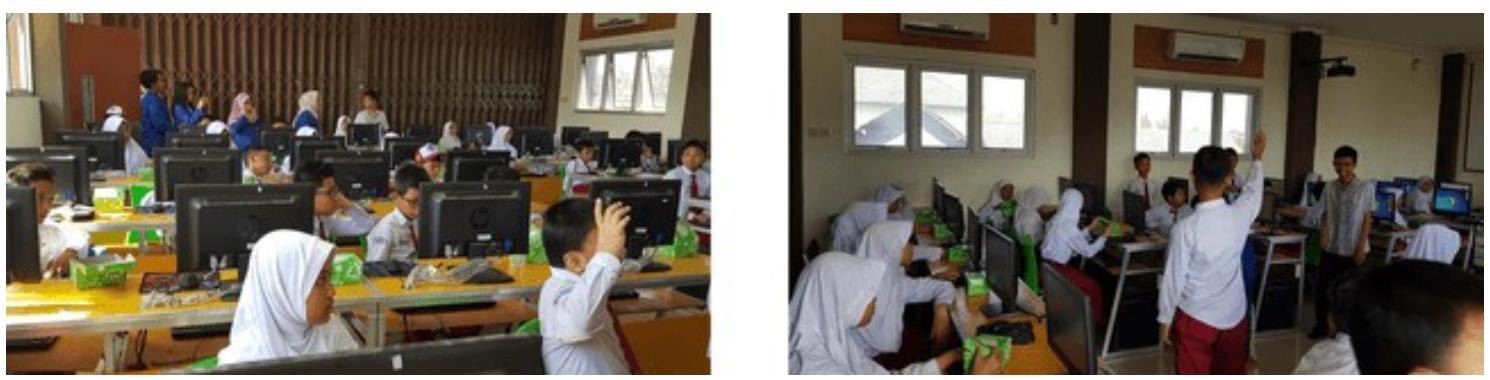

Gambar 5 Suasana Pelaksanaan Praktek

Untuk mempermudah akses alamat internet yang akan dipakai, kami menyingkat alamat site yang kita tuju dengan menggunakan fasilitas dari situs penyingkat alamat web yang panjang yaitu https://is.gd/, alamat yang akan kita singkat adalah https://studio.code.org/s/mc/stage/1/puzzle/1, sedangkan hasil penyingkat alamat untuk pelaksanaan tersebut adalah https://is.gd/ISBA2. Dengan adanya penyingkatan alamat tersebut, diharapkan para siswa peserta dapat dengan mudah mengetikkan alamat tersebut dan dapat dengan segera memulai pelaksanaan praktikum game.

Dalam praktikum game awal, dimulai dengan permainan di level 1 . Pada level 1 ini, peserta 
dihadapkan oleh permasalahan yang sederhana, yaitu bagaimana caranya agar tokoh utama dapat mencukur bulu domda yang ada di hadapannya. Solusi untuk level 1 adalah dengan menempatkan perintah maju sebanyak 2 kali, karena kita akan maju ke arah tokoh utama menghadap untuk menghampiri domba tersebut. Kemudian, setelah perintah maju, maka perintah untuk mencukur kita juga harus letakkan di area koding yang sudah disediakan dibagian kanan. Setelah semua perintah diletakkan kita bisa menjalankan perintah tersebut dengan cara klik tombol jalankan, maka tokoh utama akan berjalan dua kotak lalu mulai mencukur domba tersebut, misi level 1 selesai (Gambar 6).

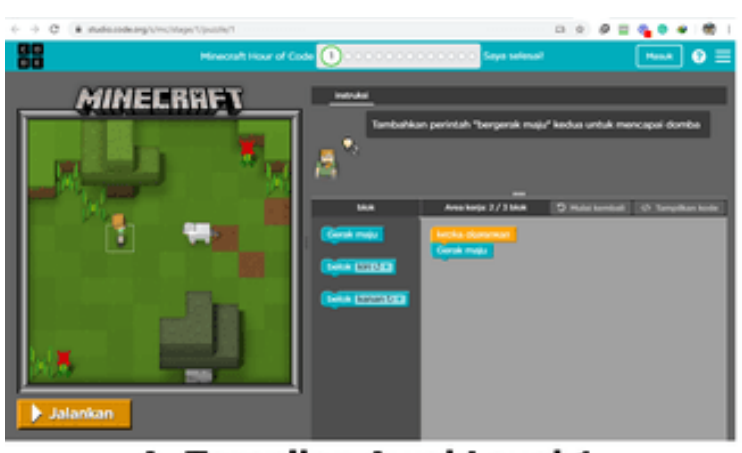

A. Tampilan Awal Level 1

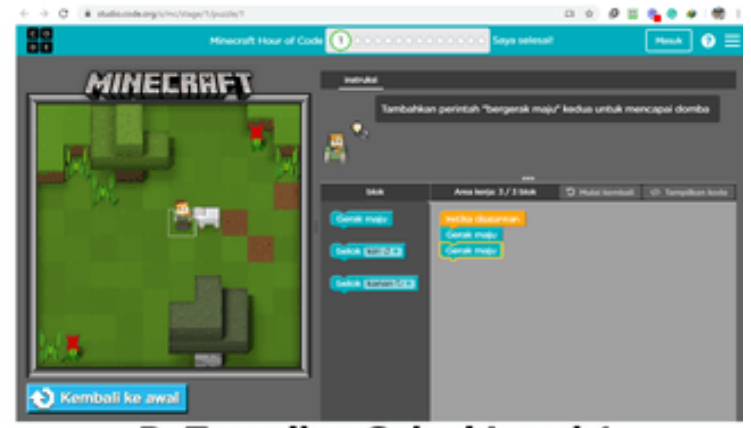

B. Tampilan Solusi Level 1

Gambar 6 Problem dan Solusi untuk Level 1

Pada tiap level yang berhasil diselesaikan, kotak pertanyaan untuk mengulangi permainan atau melanjutkan ke level yang lebih tinggi akan muncul, hal ini bertujuan agar, jika siswa yang ingin memainkan permainan yang ditemukan solusinya, mereka dapat mengulanginya kembali, jika tidak maka mereka bisa memainkan level yang lebih lanjut (Gambar 7).

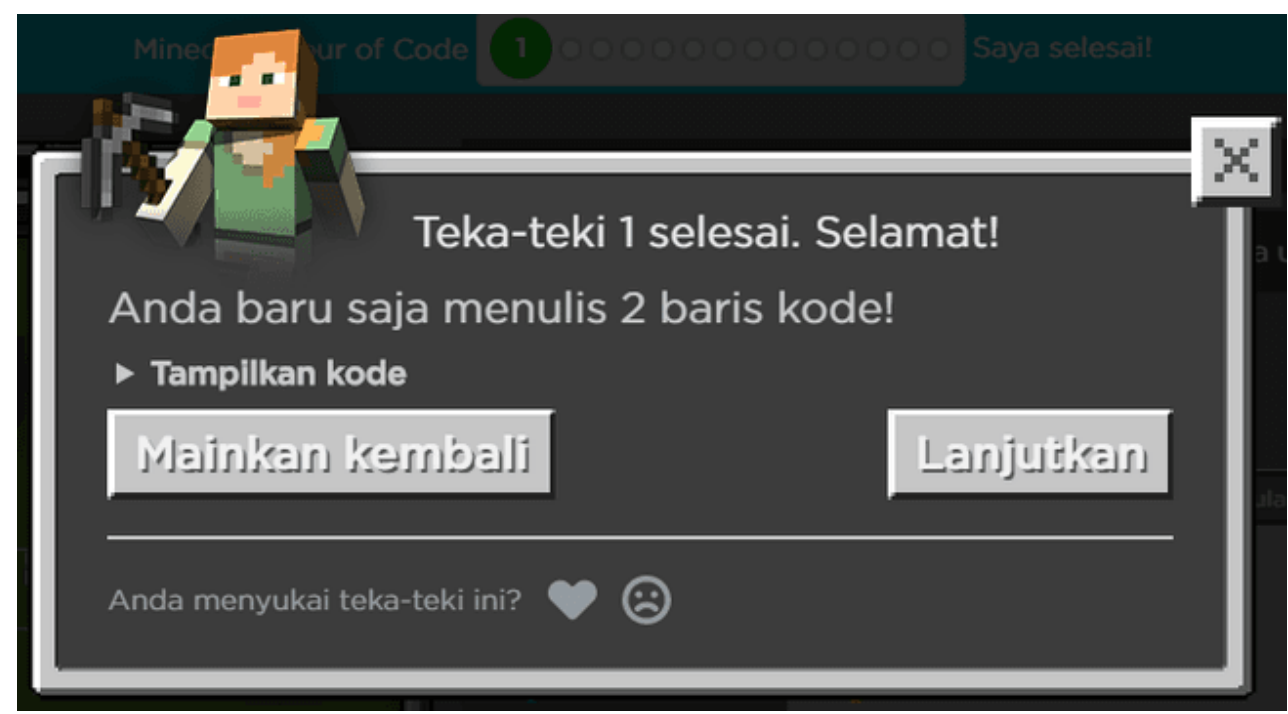

Gambar 7 Tampilan disaat berhasil menemukan solusi untuk permasalahan

Dalam permainan ini terdiri dari 14 level, dimulai dari level 1 sampai dengan level yang terakhir yaitu level 14. Pada level ke 14, permasalahan yang disediakan adalah kreativitas dari para pemain. Dimana tokoh utama ditempatkan pada area hutan, dari area itu mereka dituntut untuk melakukan kreativitas untuk melakukan sesuatu, baik untuk menebang pohon, atau membangun rumah dan lain sebagainya (Gambar 8). 


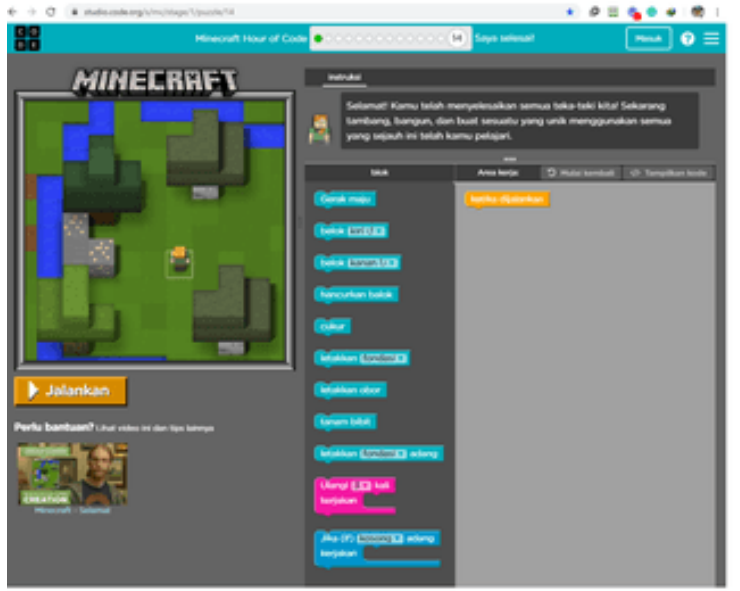

A. Tampilan Awal Level 14

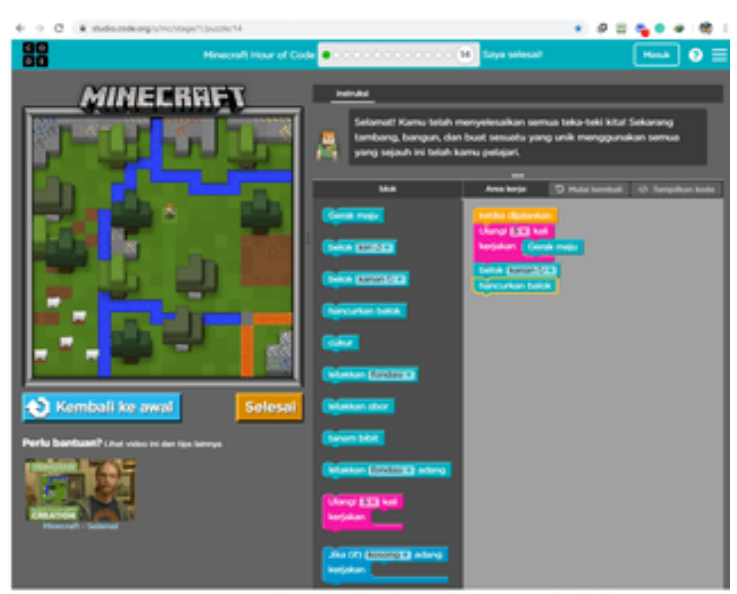

B. Tampilan Solusi Level 14

Gambar 8 Problem dan Solusi untuk Level terakhir (14)

Pada saat semua level dapat terselesaikan termasuk level terakhir, yaitu level 14, maka pertanyaan yang akan muncul adalah seperti pada (Gambar 9), dimana pertanyaan itu berisikan pilihan untuk dapat bermain kembali dengan tanpa batasan waktu dan solusi, atau mengakiri permainan untuk mendapatkan serifikat. Dalam proses praktik, alat ukur yang akan dipakai untuk mengetahui tingkat keberhasilan dari Hasil dari pelatihan ini memakai leveling yang sudah disediakan oleh website yang dipakai. Dimana leveling yang ada itu sudah didesain sedemikian rupa agar pemain dari game tersebut dalam tiap levelnya dapat mengembangkan kemampuan dalam menggunakan alat-alat / fungsi-fungsi yang selalu bertambah untuk menangani masalah yang dihadapinya. Dari 40 peserta yang mengikuti pelatihan ini, ada 35 anak yang berhasil menyelesaikan permainan tersebut dengan tepat waktu.

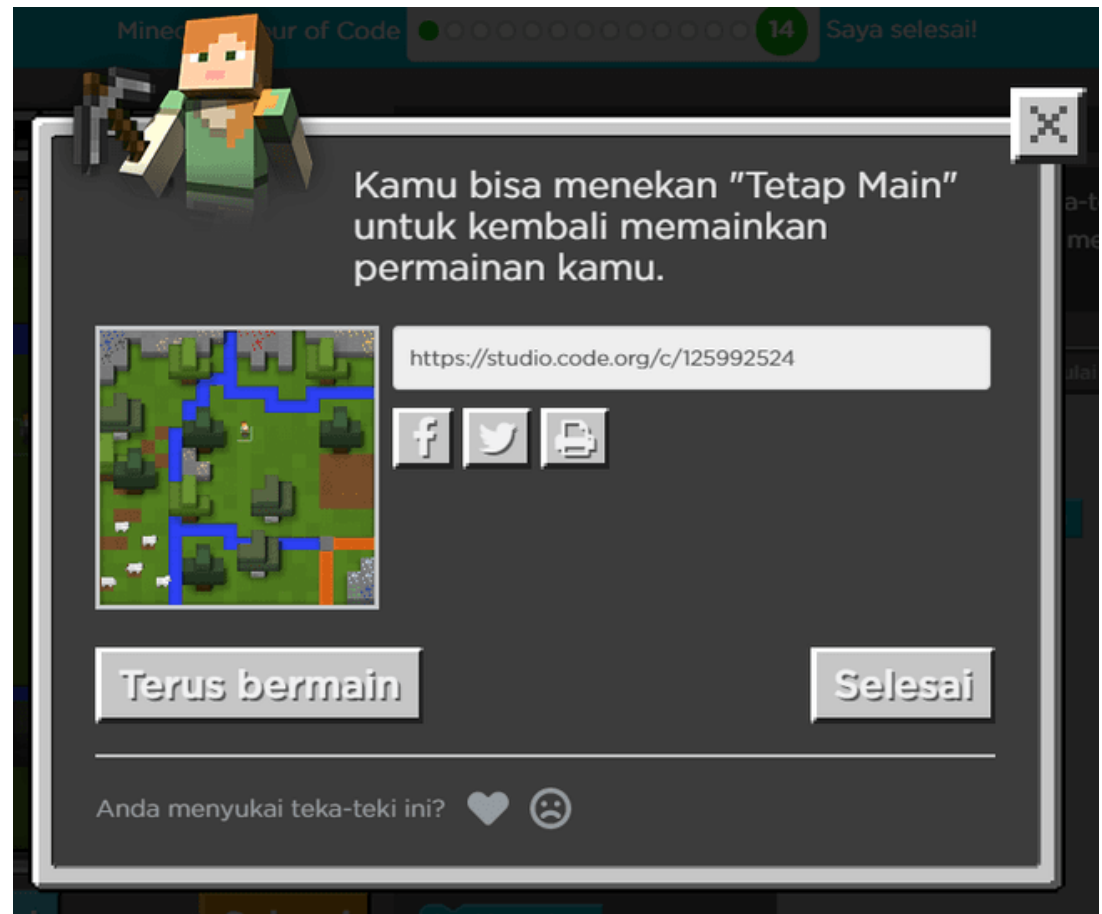

Gambar 9 Tampilan disaat menemukan solusi untuk level akhir

Untuk dapat mencetak sertifikat, pemain harus memilih untuk selesai, sehingga tampilan untuk mencetak sertifikat akan muncul dan peserta diminta untuk memasukkan nama yang akan digunakan untuk mencetak dalam sertifikat tersebut (Gambar 10). 


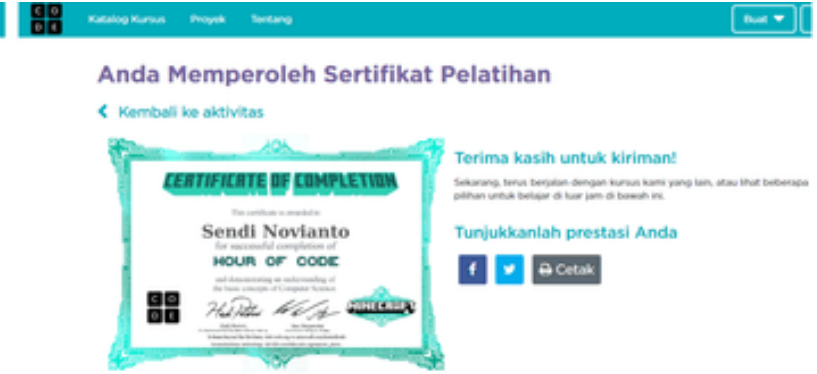

A. Tampilan Input Nama Sertifikat

B. Tampilan Sertifikat Siap Cetak

Gambar 10 Proses penulisan nama pada sertifikat

Setelah nama dari pemain diisikan pada bagian kotak isian yang tersedia, maka peserta tinggal mengklik tombol cetak untuk menghasilkan tampilan sertifikat dengan nama yang tercetak didalamnya, hasil cetakan sertifikat dapat dilihat pada Gambar 11 dibawah ini.

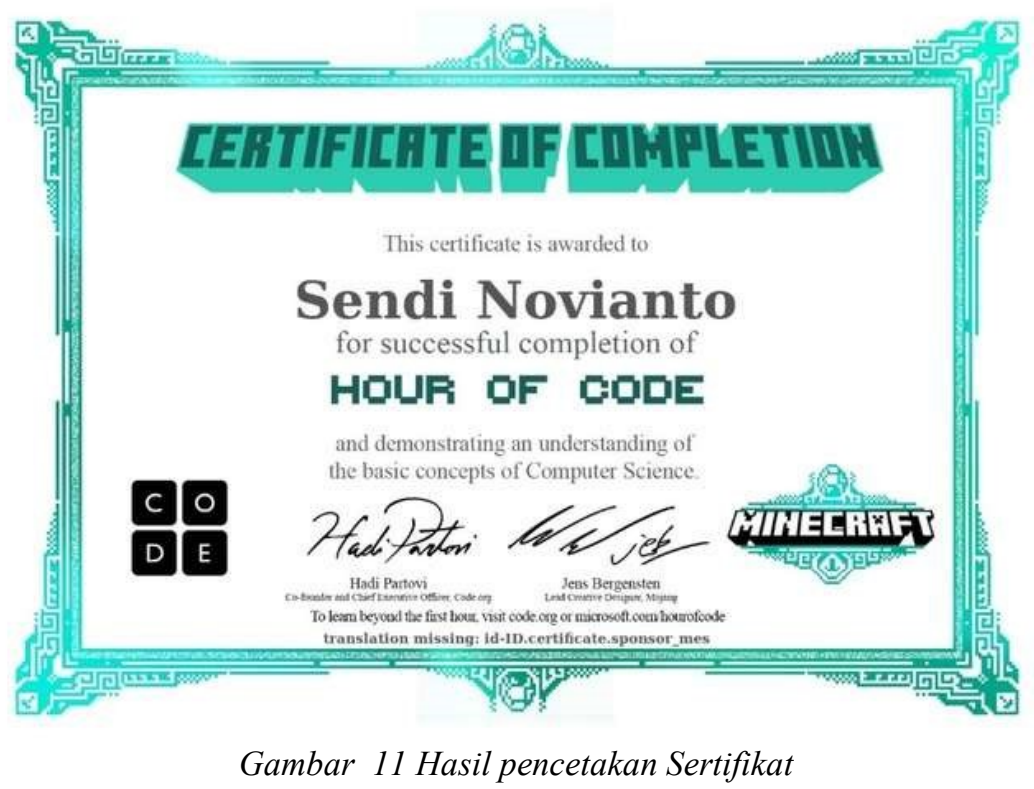

Berikut ini adalah sertifikat pagi para peserta yang sudah menyelesaikan permainan tersebut sampai dengan level terakhir, semua peserta mampu menyelesaikan semuanya. Sehingga seluruh peserta mendapatkan sertifikat dibawah ini dengan nama masing-masing yang tercetak didalamnya (Gambar 12). 


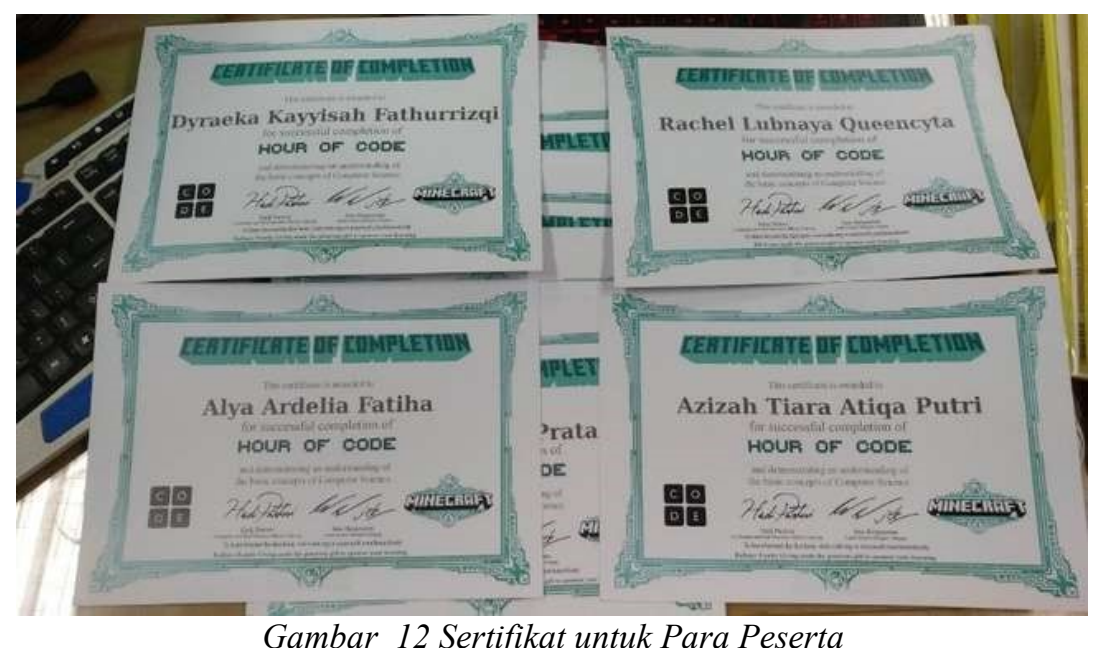

Semangat dan rasa penasaran yang tinggi dari para peserta disertai dengan dorongan semangat dari para pendamping menjadikan semangat yang membuat para peserta dapat menyelesaikan semua level pada permainan tersebut.
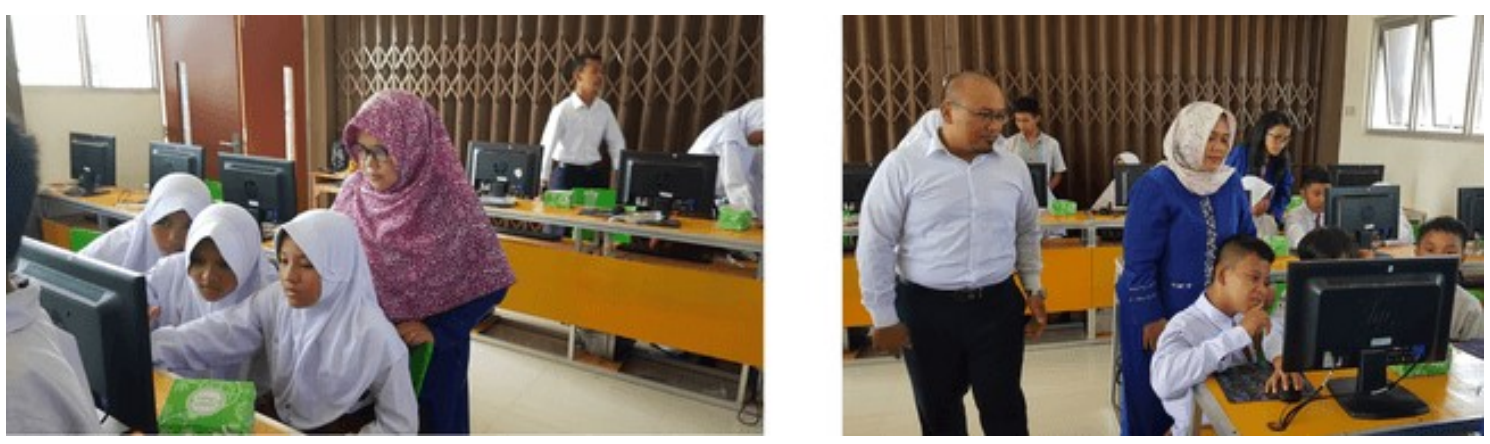

Gambar 13 Suasana Pendampingan Pelaksanaan Praktek
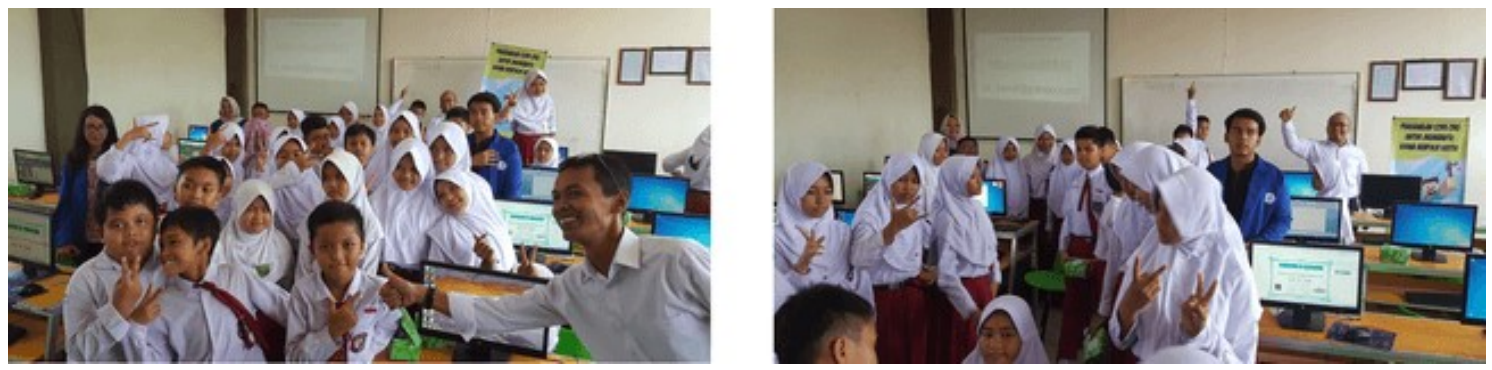

Gambar 14 Foto Bersama Setelah Menyelesaikan Praktek

\section{KESIMPULAN DAN SARAN}

Hasil dari pelatihan ini, para peserta yaitu murid-murid SD ISBA 2 Semarang merasa lebih semangat dalam memecahkan permasalahan yang ada dalam game simulasi yang diberikan. Dengan adanya bekal pemahaman akan masalah yang dihadapi disertai dengan langkah-langkah solusi yang bisa menyelesaikan masalah yang dihadapi tersebut, para siswa bisa lebih optimal dalam memilih solusi-solusi yang praktis dan cepat pada masalah yang dihadapi di dunia nyata. Pada dasarnya anak-anak selalu mempraktekkan apa yang dilihat dan 
dilakukannya dari dunia game ke dalam dunia nyata. Sedangkan untuk mitra sendiri, mereka mendapatkan pengetahuan berupa adanya situs-situs layanan online yang menyediakan pembelajaran logika dengan cara bermain. Dengan adanya pendampingan sewaktu pelatihan, diharapkan mitra mendapatkan pengalaman cara untuk mengajarkan logika kepada murid-murid SD ISBA 2 Semarang untuk kedepannya, sehingga nantinya juga dapat dimasukkan kedalam kurikulum pembelajaran yang dapat menjadikan bekal kepada murid-murid angkatan baru agar dapat lebih memanfaatkan game untuk tujuan positif dalam rangka meningkatkan kemampuannya dalam berlogika untuk menyelesaikan masalah yang dihadapinya nantinya ketika dalam proses pembelajaran dikelas.

\section{UCAPAN TERIMA KASIH}

Pengabdian ini dapat terlaksana berkat adanya bantuan dana dari LP2M Universitas Dian Nuswantoro Semarang. Oleh karena itu, melalui abdimas ini kami mengucapkan banyak terima kasih kepada LP2M Universitas Dian Nusawantoro Semarang, selain itu kami juga mengucapkan terima kasih kepada Team Pengabdi serta semua pihak di SD ISBA 2 Semarang dan juga Asisten mahasiswa TI Universitas Dian Nuswantoro Semarang yang telah meluangkan waktunya untuk bisa membantu kami dalam proses pengabdian.

\section{DAFTAR PUSTAKA}

[1] A. R. Ridwan and Mintohari, "PENINGKATAN KETERAMPILAN BERPIKIR INDUKTIF DAN HASIL BELAJAR IPA SISWA SD MELALUI PENERAPAN MODEL PEMBELAJARAN BERPIKIR INDUKTIF," JPGSD, vol. 5, no. 3, p. 522, 2017.

[2] W. Wijayanti and S. Hariani, "PENGARUH PENGGUNAAN MEDIA PANGGUNG BONEKA TERHADAP KETERAMPILAN MENYIMAK DONGENG SISWA KELAS 1 SD

LABORATORIUM UNESA," JPGSD, vol. 5, no. 3, p. 631, 2017.

[3] D. W. Listiya and Siradjudin, "PENERAPAN MODEL ROLE PLAYING UNTUK MENINGKATAN HASIL BELAJAR SISWA PADA MATA PELAJARAN IPS DI KELAS IV SDN KEDUNGKEMBAR PRAMBON SIDOARJO,”, JPGSD, vol. 5, no. 3, p. 671, 2017.

[4] P. E. Febrianti and Suprayitno, "PENERAPAN STRATEGI PEMBELAJARAN EVERYONE IS A TEACHER HERE UNTUK MENINGKATKAN KETERAMPILAN PEMECAHAN MASALAH SOSIAL SISWA PADA MATA PELAJARAN IPS KELAS IV SDN JATILANGKUNG MOJOKERTO,”JPGSD, vol. 5, no. 3, p. 684, 2017.

[5] Amrah, "Perkembangan Moral Anak Usia Sekolah Dasar," Publikasi, vol. III, no. 1, pp. 20-25, 2013.

[6] S. Listyaningsih and M. H. Abdullah, "PENINGKATAN HASIL BELAJAR MELALUI PENERAPAN MODEL PEMBELAJARAN KOOPERATIF NUMBERED HEAD TOGETHER DI SDN KEBRAON I SURABAYA,” JPGSD, vol. 5, no. 3, p. 598, 2017.

[7] D. M. Sari and M. Sukidi, "MENINGKATKAN KETERAMPILAN MENYIMAK MELALUI MEDIA BONEKA TANGAN (HAND PUPPET) PADA PELAJARAN BAHASA INDONESIA SISWA KELAS II SDN BLIMBING JOMBANG KOTA JOMBANG,” JPGSD, vol. 5, no. 3, p. $543,2017$.

[8] P. N. Hayati and I. Rahmawati, "Pengaruh Media Tangsapan Terhadap Hasil Belajar Pada Materi Pengukuran Panjang Siswa Kelas 3 Tema 6 Subtema 1 SDN Babatan I Surabaya,” JPGSD, vol. 5, no. 3, p. 1, 2017.

[9] A. N. Hika and Suryanti, "PENGARUH PENGGUNAAN MEDIA ULAR TANGGA MODIFIKASI TERHADAP HASIL BELAJAR SISWA KELAS V SEKOLAH DASAR,” JPGSD, vol. 5, no. 3, p. 694, 2017.

[10] A. S. Amilyana and Y. Yermiandhoko, "PENGEMBANGAN CD INTERAKTIF BERBASIS FLASH MATERI STRUKTUR BUMI SEBAGAI ALTERNATIF MEDIA PEMBELAJARAN IPA DI KELAS V SDN JIKEN, SIDOARJO,” JPGSD, vol. 5, no. 3, p. 651, 2017. 